\title{
Boundary Crossing for Education Continuity: Exploring WhatsApp's Potential in Botswana During and Beyond the Pandemic
}

\author{
https://doi.org/10.3991/ijim.v16i02.27283 \\ Dawn Lyken-Segosebe ${ }^{(凶)}$, Gladys Gamariel, Kelebonye Bagai \\ Botswana International University of Science and Technology, Palapye, Botswana \\ segosebedabiust.ac.bw
}

\begin{abstract}
Based on a conceptualization of WhatsApp as a boundary object that permits educational institutions to cross over from in-school teaching to out-of-school teaching, this study investigated the viability of WhatsApp as a mobile learning ( $\mathrm{m}$-Learning) technology tool for the continuity of teaching and learning in Botswana during and beyond the COVID-19 pandemic. Utilizing a narrative review of the literature, we found that WhatsApp's viability is supported by Botswana's high mobile phone penetration rate, the extensive coverage of the country's mobile broadband network, reduced domestic internet prices and research findings of WhatsApp's technological, educational and academic advantages elsewhere. However, teachers require training to develop relevant technological and pedagogical competences. WhatsApp's viability also requires inclusive access for all children including those from rural poor families and living with disabilities, and the protection of children learning online from mobile phone dependency and exposure to potentially harmful content and abuse.
\end{abstract}

Keywords-Botswana, boundary crossing, COVID-19, educational technology, m-learning, WhatsApp

\section{Introduction}

COVID-19 is wreaking havoc on the lives of children, students, and youth. The disruption of societies and economies caused by the pandemic is aggravating the pre-existing global education crisis and is impacting education in unprecedented ways [1].

After the World Health Organization (WHO) declared the novel coronavirus disease (COVID-19) as a pandemic on $11^{\text {th }}$ March 2020, countries around the world responded by implementing social distancing measures to slow the transmission of the disease. The Government of Botswana closed all educational institutions on $23^{\text {rd }}$ March 2020 and declared a national lockdown for the seven-week period of $2^{\text {nd }}$ April-2 ${ }^{\text {st }}$ May 2020 
in order to prevent the spread of the disease. When the lockdown was lifted on $22^{\text {nd }}$ May 2020, this intervention was considered a success since relative to the situation in several other upper-middle-income countries and neighboring countries, Botswana had recorded 30 confirmed cases, the majority of which were truck drivers transiting to and from neighboring countries.

The requirement for a national lockdown emphasized that the COVID-19 pandemic had created several global crises, foremost being a health crisis but also economic and educational crises. The pandemic disrupted teaching and learning around the world to the extent that by mid-April 2020, 94 percent of learners worldwide were affected, representing 1.58 billion children and youth from pre-primary to higher education in 200 countries [2].

In Botswana, the closure of educational institutions and the subsequent national lockdown impacted 600,000 primary and secondary students and 35,000 teachers, amongst others in the education sector. Public and private education administrators faced the challenge of how to effectively implement teaching-learning processes at a time when social distancing measures were required to slow the transmission and spread of the disease. A rapid response was warranted to mitigate the pandemic's potential negative effects on educational attainment.

An immediate response came from three sources. First, within a week of the national lockdown, the country's Ministry of Basic Education which administers public primary and secondary education, implemented a series of measures to support learners during the lockdown: learners were provided with learning material for home study; radio lessons time was extended for primary school learners by one hour daily during Monday to Friday; television lessons time was extended for both primary and secondary school learners by two hours three days a week; Botswana Open University's (BOU) online secondary school material was made publicly available; and 23 online learning sites relevant to the school curriculum were assessed and cleared for use by learners [3].

Second, within five days of the national lockdown, Botswana's three mobile service providers (Botswana Telecommunications Corporation Limited, Mascom Wireless and Orange Botswana) announced they were offering national access to online learning platforms on free or discounted price bases while working towards increasing network capacity and equipment upgrades [4].

Third, the Botswana Communications Regulatory Authority (BOCRA), the country's regulatory body with oversight of all broadcasting, internet and telecommunications services, secured substantial reductions in the prices for internet data bundles and an increase in data volumes at unchanged prices from Mascom Wireless and Orange Botswana. Mobile data costs were reduced by between $11 \%$ and $46 \%$ on average, making mobile internet even more accessible across the country [5].

Botswana's population size was 2.35 million in 2020 [6]. In January 2020, just prior to the declaration of the pandemic, WhatsApp was the top messenger app in use across Botswana [7]. The country had 3.78 million mobile connections, 1.09 million internet users and 1 million social media users [7]. However, despite WhatsApp's popularity as a medium of communication nationally and BOCRA's negotiation of reduced data prices and increased volumes for mobile data, no attempt was made by the public education system to officially adopt the WhatsApp platform as a business continuity 
model to bring teachers and students together for daily instructional sessions, and connect school administrators, parents and students for administrative purposes.

\subsection{Study purpose and research questions}

This study sought to determine the viability of WhatsApp as a mobile learning (m-Learning) technology tool for the public secondary education system in Botswana. The COVID-19 pandemic has underscored the necessity for education administrators to not only prepare technology-literate students for the digital era but to also have in place contingency plans that assure teaching and learning continuity during and beyond pandemics.

While schools resumed with contact classes one month after the national lockdown, they were closed once more a year later on $16^{\text {th }}$ July 2021 for just under two months. School closure came amid a landscape of increasing COVID-19 cases among learners, teachers and school support staff; teacher and support staff deaths from the disease; and additional waves of contagion arising from at least three of four COVID-19 variants of concern in circulation.

The World Health Organization (WHO) lists the following diseases with epidemic potential that pose the greatest risk to public health: COVID-19, CrimeanCongo haemorrhagic fever, Ebola virus disease, Marburg virus disease, Lassa fever, Middle East respiratory syndrome coronavirus (MERS-CoV), Severe Acute Respiratory Syndrome (SARS), Nipah and henipaviral diseases, Rift Valley fever, Zika and "Disease X" [8]. It is for the last item on the WHO's list of priority pathogens, the yet unknown Disease X, that Botswana's educational administrators must devise a contingency plan for future teaching and learning.

Accordingly, three research questions drove this study:

1. What factors support the use of WhatsApp as a new paradigm for secondary education teaching and learning in Botswana?

2. What challenges may limit WhatsApp's potential use for secondary education teaching and learning in Botswana?

3. What technological and pedagogical competences are critical for teachers to successfully use WhatsApp for m-learning?

The focus on secondary education derived from WhatsApp's requirement of a smartphone for its functionality. Research findings [9, 10, 11] indicate that students at the secondary education level generally tend to have high mobile phone usage rates.

This study is significant because there is a dearth of research knowledge on the feasibility of utilizing social media apps and mobile learning (m-learning) as a paradigm for teaching both primary and secondary students in Botswana. Little is also known about how digital technologies can be used to ensure that school teaching and learning processes continue in the context of the COVID-19 pandemic. The study therefore breaks new ground with regards to studies that specifically examine WhatsApp as a tool for education continuity within basic education in Botswana. This research gap is not limited to Botswana. Researchers $[12,13]$ assert that academic potential of smartphones to support m-learning is yet to be fully researched. 


\section{$2 \quad$ Literature review}

The extant literature provides a conceptual background on mobile learning, WhatsApp and WhatsApp's use in school administration.

\subsection{Mobile learning (m-Learning)}

M-Learning is the delivery of electronic learning (e-learning) materials using or mediated by handheld and mobile technologies such as personal digital assistants (PDAs), mobile phones, tablet PCs, pocket PCs, and palmtop computers [14-16]. According to Quinn [17], m-learning is:

The intersection of mobile computing and elearning: accessible resources wherever you are, strong search capabilities, rich interaction, powerful support for effective learning, and performance-based assessment. Elearning independent of location in time or space. (pp. 1-2)

Mobile learning embodies mobility of technology, learners and learning. El-Hussein and Cronje [18, p. 17] state there is mobility of technology since mobile technology, which may also function as audio-players, media-players and digital cameras, and have Wireless Application Protocol (WAP) and Wireless Fidelity (Wi-Fi) capacities, has the ability to "link to the Internet and deliver content and instruction that can enable learners to learn at anytime and anywhere in a format that is culturally prestigious among people in the same age group."

There is mobility of learners as learning can occur at any place or time. Rambe and Bere [19, p. 546] state that m-learning "potentially breaches the spatial, temporal and time zones by bringing educational resources at the disposal of the roaming learner in real time." Learning can be delivered "just-in-time," "just enough," and "just-for-me" as all learning resources - whether interacting peers, lecturers, pedagogical content, the enabling technology — are all "on-the-move" $[19,16]$.

There is also mobility of learning as the learning is received and processed within the individual context in which the learner is situated, rather than in the traditional classroom, lecture room, or computer laboratory [18, 20]. Robles et al. [21, p. 232] note that mobile learning "provides students with unlimited opportunities to achieve their learning goals through learning situations in real time and authentic interaction that makes learning meaningful, effective and different from those decontextualized traditional classrooms."

\subsection{The WhatsApp application}

Developed in 2009, WhatsApp is a cross-platform centralized messaging and voice-over-internet protocol service that offers free, simple, secure, and reliable messaging and calling [22]. It is an application that runs on mobile devices and is also accessible on a Mac or Windows 8 or higher desktop computer. Installation: The requirements for installing WhatsApp are a compatible smartphone (e.g., Android OS 4.0.3 or above, iPhone) or tablet with a sim card, an internet connection (4G/3G/2G/EDGE or Wi-Fi, as available), and a telephone number. WhatsApp creates a user account using 
the telephone number as the username. Messaging: WhatsApp uses a phone's internet connection to send free and unlimited messages. It permits broadcasting of messages to multiple contacts at once. Calling: WhatsApp uses a phone's internet connection to enable secure video and voice local and international calls with up to 8 people for free. Group Chat: WhatsApp permits end-to-end encrypted group chats (of up to 256 persons) with the sharing of multimedia - text and video messages, photos, videos and documents up to $100 \mathrm{MB}$ - using a mobile device or desktop computer [22]. WhatsApp has over 2 billion subscribers in 180 countries and is available in 60 languages. It is ranked as the most used mobile messenger app in the world with over 100 billion messages sent each day and over two billion minutes spent on WhatsApp voice and video calls per day [22].

\subsection{WhatsApp and school administration}

WhatsApp permits student-student, student-teacher, teacher-teacher, student-school administrator, parent-administrator and parent-parent communication. WhatsApp's group chat feature facilitates these various types of communication.

Applying Bower's [23] e-learning technology affordances, WhatsApp's permissionability allows the creation of closed WhatsApp groups, providing safe environments where academic discussions as well as social dialogue can take place. Its classroom groups serve five purposes within schools. First, the groups serve an organizational function, that is, they are used to communicate with students e.g., to send organizational messages, update students about the school's ongoing activities, and special events. Second, classroom groups serve an instructional function as a learning platform or learning community.

Third and fourth, nurturing a social atmosphere and encouraging dialogue and sharing among students are attributed to these classroom groups. Finally, classroom groups serve a disciplinary function as some teachers use WhatsApp to enforce discipline and influence students' behaviour [24, 13]. The broadcast feature enables teachers to assign homework to all students in the class. Teachers can hold office hours with students through individual and group voice and video calls. The share-ability, link-ability, synchronous-ability, video-produce-ability, read-ability, view-ability, listen-ability, write-ability, speak-ability, record-ability and watch-ability of WhatsApp allow teachers and students to share course information and classroom feedback, and permit peer-to-peer communication [23].

Outside the classroom, WhatsApp's group chat feature permits principals and other school administrators to share announcements, notices, timetables, report cards and invoices with parents. They can hold virtual meetings with teachers, parents and students. Parents may have their own WhatsApp groups to exchange information among themselves [25].

\section{Conceptual framework}

The study derived its conceptual framework from the conceptions of boundary crossing and boundary objects based on the works of Bernstein [26], Engeström, Engeström, and Kärkkäinen [27], Star [28-29], Suchman [30] and others and elaborated in a 
literature review conducted by Akkerman and Bakker [31]. According to Akkerman and Bakker [31], all learning involves boundaries. Educators therefore have the task to create possibilities for educational participation and collaboration across the diversity of sites, and within and across institutions (pp. 132-133).

A boundary can therefore occur between learning that takes place at a school site and that which takes places outside school (e.g., at home). Boundary crossing is required to bridge this gap. Suchman [30] defines boundary crossing as "a person's transitions and interactions across different sites" [31, p. 140]. People play a critical role in crossing boundaries. Educators are therefore "brokers, boundary crossers, and boundary workers" (p. 140). Objects also play a role in crossing boundaries. Akkerman and Bakker [31, p. 133, 140] state that these objects are "artifacts doing the crossing by fulfilling a bridging function [28]" and are "organic arrangements that allow different groups to work together [29]." The researchers also state that "as black boxes, boundary objects tend to be invisible or taken-for-granted mediations that translate across sites but, when carefully considered or opened up, may provide learning opportunities [32]."

In this study, WhatsApp is conceived as a boundary object or practice that performs a bridging function. It permits crossing at the boundary between learning that takes place at a school site and that which takes place outside school. Akkerman and Bakker [31] emphasize that to be successful, a boundary object must "capture multiple perspectives" (p.140). In our study this translates to acceptance by participants in Botswana's basic education system - the Ministry of Basic Education, public school administrators, parents and students.

Akkerman and Bakker [31, pp. 141-148] outline four mechanisms through which the learning potential of a boundary crossing may occur. With WhatsApp as the boundary object or practice fulfilling a bridging role, there must be:

1) Identification - the new practice becomes known or delineated relative to others and takes on a "legitimating coexistence" (p. 141), that is, WhatsApp becomes recognized as a legitimate alternative form of teaching and learning that takes place outside school vis-à-vis within school.

2) Coordination - the new practice serves as a mechanism that allows the learning boundary to be overcome so that continuity is established. Learning via WhatsApp is therefore communicated as an alternative to within-school learning, routinized and established as having "boundary permeability" (p. 144), that is, it permits seamless movement between the two practices-learning within-school and learning outside of school.

3) Reflection-WhatsApp develops an identity as people's (the Ministry of Basic Education, public school administrators, parents and students) perspectives are expanded to consider it as a viable alternative learning practice.

4) Transformation-WhatsApp becomes the new "boundary practice" (p. 146) as a result of a process of a) "confrontation with some problem" (i.e., the effects of the COVID-19 pandemic on educational attainment) or "disruption in the current flow of work" that "forces the intersecting worlds to seriously reconsider their current practices and the interrelations" (p. 147); b) recognition of a shared problem spacei.e. that teaching and learning disruption is national; c) emergence of a new hybrid practice - i.e. WhatsApp; d) crystallization—i.e. embedding WhatsApp as a national 
online teaching and learning tool so that it has a real effect; and e) "continuous joint work" or "negotiation of meaning" at the boundary-i.e. with the continuous engagement of key stakeholders to ensure WhatsApp's universal acceptance.

\section{Methodology}

A semi-systematic or narrative review of the extant literature was conducted to investigate what is known about WhatsApp as a teaching and learning tool and its usage in secondary schools generally and in Botswana, and the coverage, services and service charges of voice and internet service providers in Botswana.

Four databases-EBSCO, ProQuest, ERIC and Google Scholar-and Google were searched for relevant peer-reviewed journal articles, reports and peer-reviewed conference papers. The terms "WhatsApp" and "m-learning" were searched for in titles, abstracts and keywords of each peer-reviewed journal article found in these databases and online generally. The inclusion criteria were (i) peer-reviewed journals published in English between the years 1980 and 2020; (ii) research that focused on (a) the use of WhatsApp in secondary education and (b) the role of mobile learning on teaching and learning; (iii) articles with accessible abstracts and full text; (iv) peer-reviewed conference papers. Exclusion criteria were editorials, commentaries, conference abstracts, reviews, and duplicates.

Reports prepared under the auspices of Statistics Botswana, the Botswana Communications Regulatory Authority (BOCRA), International Telecommunication Union, United Nations Educational, Scientific and Cultural Organization (UNESCO) and the World Bank were searched for publications related to mobile learning, ICT competence frameworks, digital education, technology-enabled learning and educational responses to the impacts of the COVID-19 pandemic. Facebook pages of local news agencies were searched for videos and articles related to basic education, and internet and mobile service provision posted during and subsequent to the period of national lockdown.

\section{$5 \quad$ Findings}

Findings are organized according to the three research questions that guided this study.

Research Question One: What factors support the use of WhatsApp as a new paradigm for secondary education teaching and learning in Botswana?

WhatsApp's viability as a paradigm for teaching and learning in secondary education derives from research findings of advantages derived from WhatsApp's use in secondary education in other countries, Botswana's high mobile phone penetration rate, the extensive coverage of the country's mobile broadband network, reduced internet prices, and the existing availability of online secondary education learning platforms in the country. 


\subsection{Research evidence on WhatsApp's use in secondary education}

The extant literature on WhatsApp's use in secondary education is limited but some insight is available on the app's use within secondary schools in Israel and Iran. Perspectives were obtained from teachers [24] and students participating in studies undertaken in Israel $[33,13]$. Students' relative performance on assessments in experimental (using WhatsApp) and control groups was also obtained for students in Iran [34] and Israel [33]. In each school, classrooms were organized as WhatsApp groups. Students were members of several WhatsApp groups: a group comprising their entire class and its teacher, study groups, and additional groups with different compositions of students and teachers for specific topics [13].

WhatsApp's technical and educational advantages. Teachers identified Technical Advantages arising from WhatsApp's use within the classroom [24]. Teachers noted that the app was simple, low cost (if any) and private in comparison to other social networks such as Facebook and Twitter. They recognized its immediate accessibility since substantial teacher and student training and major administrative support and infrastructure were not required for its use. According to Bouhnik \& Deshen [24, p. 229],

WhatsApp might be the first technology that entered the class without any training or administrator supervision, as teachers and students are using it in their private life, and its advantages enabled it to be become, naturally, an educational technology.

Teachers identified several Educational Advantages. WhatsApp's open style discussion enabled teachers to get to know their students in depth and created a positive atmosphere and a sense of belonging among students. Students were able to dialogue and work as a team to solve problems and deal with challenges. The interpersonal relationship between teachers and students was enhanced as students felt more comfortable about approaching their teachers online to discuss a range of issues [24].

Some students found it easier to be open and "express myself on WhatsApp, with all the emoticons" rather than talk to teachers face to face. Other students stated that they could 'hide' within the group - they could raise issues they would not normally raise face-to-face or through a private WhatsApp message. Shy or introverted students preferred the textual interface. Bouhnik and Deshen [24, p. 227] concluded that:

The ability to access information, content, support, and personal aid on a regular basis, regardless of the physical presence of a student in class, potentially can enhance the learning process. Such options appear to be of especial significance for students who come from an un-nurturing environment and need encouragement and someone to whom they may direct their questions (Chipunza, 2013).

Students liked the app's privacy; the fact that only their profile picture was shared on WhatsApp rather than information related to their personal life that tend to be publicly available on Facebook [13].

WhatsApp's academic advantages: learning and test scores. WhatsApp also permitted Academic Advantages such as "easy and quick transference" of links to learning materials, teacher availability to answer students' questions after hours, the continuation of learning beyond class hours, and the ability to correct students' mistakes 
immediately. Student stated that WhatsApp enabled teachers to be available to answer students' questions and address requests real-time, including after school hours. The public nature of WhatsApp classroom groups enabled the entire group to learn from answers given to those students who asked questions $[33,13]$. Bouhnik and Deshen [24] found that "even the shy students can see other student's questions and enjoy the answers shared with everyone."

According to Cetinkaya [33], students recognized WhatsApp as a pedagogical tool for their learning and benefited from receiving information texts accompanied by images related to those texts. This is in keeping with Marshall's [35] findings that people remember $10 \%$ of what they read, $20 \%$ of what they hear, $30 \%$ of what they see and $50 \%$ of what they hear and see. By enabling students to read and hear through audio and video sources and multiple types of text, learning and retention are enhanced. When Jafari \& Chalak [34] investigated the role of WhatsApp in the vocabulary learning improvement of Iranian junior high school EFL students who were learning English as a foreign language, these researchers found that vocabulary learning among students receiving instructions via WhatsApp was more effective than learning in traditional classrooms. Higher scores in an achievement test were reported for learners in a group where WhatsApp was used as supportive technology as compared to those in a traditional classroom environment [33].

\subsection{Mobile penetration and smartphone costs in Botswana}

Botswana's mobile phone penetration rate supports WhatsApp's viability as a paradigm for teaching and learning in secondary education. WhatsApp requires a compatible smartphone and internet connectivity for functionality. Regarding the telephony aspect of this functionality, the cost of a suitable smartphone starts at around US\$ 38 . Furthermore, Botswana has one of the world's highest mobile phone penetration rates, rivalling United States of America (81.6\%), United Kingdom (78.4\%) and Germany $(77.6 \%)$ [36]. Its mobile penetration rate was over $191 \%$ of the country's population in December 2020 [37]. While there were 3.78 million mobile phone subscriptions with multiple SIM card ownership before the pandemic hit in the first quarter of 2020, subscriptions reached 4.02 million by March 2020 [38-39].

\subsection{National mobile broadband network coverage}

WhatsApp's requirement of internet connectivity for functionality is supported by the extensive national coverage of Botswana's mobile broadband system. The mobile broadband penetration rate was $112 \%$ in May 2021 and national network coverage was 98\% [37]. Botswana Fibre Networks Ltd (BoFiNet) is the country's largest internet wholesaler and provides the backbone infrastructure for the national broadband system. The company has national fibre of $10,600 \mathrm{~km}$ countrywide connecting cities, major towns, villages and selected strategic locations. Its infrastructure is used by BTC, Mascom Wireless, Orange Botswana and other internet service providers. BoFiNet peers with the world's biggest content providers including Google, Microsoft, Netflix, Facebook, Apple and Akamai. Facebook is WhatsApp's parent company [40]. 


\subsection{Internet affordability in Botswana}

Botswana ranks $13^{\text {th }}$ globally and $2^{\text {nd }}$ in Africa on the Affordability Drivers Index (ADI), a tool that assesses how well a country's policy, regulatory, and overall supply-side environment is working to lower industry costs and create more affordable broadband [41]. Reduced internet rates enhance the affordability of access to WhatsApp. The regulatory body Botswana Communications Regulatory Authority (BOCRA) continuously negotiates substantial price reductions for data bundles with internet service providers. On average, mobile data costs were reduced by between $11 \%$ and $46 \%$ on average in 2020 [5]. Table 1 indicates the June 2021 internet service rates for the three mobile service providers-Botswana Telecommunications Corporation Limited (BTC), Mascom Wireless and Orange Botswana. The prices give an indication of the relative affordability of internet services for access to WhatsApp.

Table 1. Internet rates US\$ (June 2021)—Botswana Telecommunications Corporation Limited, Mascom Wireless and Orange Botswana

\begin{tabular}{|c|c|c|c|c|c|c|}
\hline \multirow{5}{*}{$\begin{array}{l}\text { Rate Period } \\
1 \text { day }\end{array}$} & \multicolumn{2}{|c|}{$\begin{array}{c}\text { Botswana } \\
\text { Telecommunications } \\
\text { Corporation Limited }\end{array}$} & \multicolumn{2}{|c|}{ Mascom Wireless } & \multicolumn{2}{|c|}{ Orange Botswana } \\
\hline & \multirow{4}{*}{$500 \mathrm{MB}$} & \multirow[t]{4}{*}{$\$ 0.50$} & $25 \mathrm{MB}$ & $\$ 0.20$ & $25 \mathrm{MB}$ & $\$ 0.20$ \\
\hline & & & $100 \mathrm{MB}$ & $\$ 0.50$ & $100 \mathrm{MB}$ & $\$ 0.50$ \\
\hline & & & $500 \mathrm{MB}$ & $\$ 1.00$ & $500 \mathrm{MB}$ & $\$ 1.00$ \\
\hline & & & $1 \mathrm{~GB}$ & $\$ 1.80$ & $1 \mathrm{~GB}$ & $\$ 1.80$ \\
\hline 2 days & & & $1 \mathrm{~GB}$ & $\$ 2.00$ & $1 \mathrm{~GB}$ & $\$ 2.00$ \\
\hline \multirow[t]{2}{*}{1 week } & \multirow[t]{2}{*}{$500 \mathrm{MB}$} & \multirow[t]{2}{*}{$\$ 1.50$} & $1 \mathrm{~GB}$ & $\$ 3.90$ & $1 \mathrm{~GB}$ & $\$ 3.50$ \\
\hline & & & $2 \mathrm{~GB}$ & $\$ 4.50$ & $2.5 \mathrm{~GB}$ & $\$ 5.00$ \\
\hline \multirow[t]{2}{*}{2 weeks } & & & $1 \mathrm{~GB}$ & $\$ 4.90$ & $1.5 \mathrm{~GB}$ & $\$ 6.00$ \\
\hline & & & $3 \mathrm{~GB}$ & $\$ 8.50$ & $4 \mathrm{~GB}$ & $\$ 8.00$ \\
\hline \multirow[t]{7}{*}{1 month } & $500 \mathrm{MB}$ & $\$ 6.10$ & $2 \mathrm{~GB}$ & $\$ 6.90$ & $2 \mathrm{~GB}$ & $\$ 6.90$ \\
\hline & $1 \mathrm{~GB}$ & $\$ 7.50$ & $4 \mathrm{~GB}$ & $\$ 9.90$ & $3 \mathrm{~GB}$ & $\$ 8.90$ \\
\hline & $3 \mathrm{~GB}$ & $\$ 9.00$ & $8 \mathrm{~GB}$ & $\$ 14.90$ & $4 \mathrm{~GB}$ & $\$ 9.90$ \\
\hline & $5 \mathrm{~GB}$ & $\$ 11.00$ & $16 \mathrm{~GB}$ & $\$ 27.90$ & $6 \mathrm{~GB}$ & $\$ 11.90$ \\
\hline & $10 \mathrm{~GB}$ & $\$ 22.00$ & $32 \mathrm{~GB}$ & $\$ 52.50$ & $12 \mathrm{~GB}$ & $\$ 21.90$ \\
\hline & $15 \mathrm{~GB}$ & $\$ 30.00$ & & & $18 \mathrm{~GB}$ & $\$ 29.90$ \\
\hline & & & & & $32 \mathrm{~GB}$ & $\$ 49.90$ \\
\hline
\end{tabular}

Notes: 1. Adapted from online data presented on the websites of Botswana Communications Regulatory Authority (BOCRA) and Botswana Telecommunications Corporation Limited.

2. Prices have been converted from Botswana Pula to US dollar using an average rate of US\$1= BWP10.

BoFiNet has contributed to these lowered prices as the demand for higher bandwidth by its customers (e.g., Mascom Wireless and Orange Botswana) have resulted in reduced costs/Mbps since costs are spread over increased bulk orders. Furthermore, Botswana's landlocked nature (with surrounding countries being Namibia, South Africa, Zambia and Zimbabwe) creates an advantage of access to multiple international entry connectivity links from neighboring countries that in turn provide redundancies and a high availability of services for the country's internet service providers [42]. 
Table 2 below presents a comparison of mobile broadband prices in Botswana and other countries in the Southern African Development Community (SADC) region. The data indicate that Botswana's prices as at September 2020 were very competitive, thus confirming the affordability of access to WhatsApp.

Table 2. Prepaid mobile broadband prices: September 2020 (in Botswana Pula)

\begin{tabular}{|l|c|c|c|}
\hline $\begin{array}{c}\text { 30-Day } \\
\text { Internet } \\
\text { Package }\end{array}$ & $\begin{array}{c}\text { Botswana } \\
\text { (Botswana Telecommunications } \\
\text { Corporation) }\end{array}$ & $\begin{array}{c}\text { South Africa } \\
\text { (MTN, Vodacom) }\end{array}$ & $\begin{array}{c}\text { Namibia } \\
\text { (Telecom) }\end{array}$ \\
\hline $1 \mathrm{~GB}$ & $\$ 7.50$ & $\$ 7.17$ & $\$ 10.07$ \\
\hline $3 \mathrm{~GB}$ & $\$ 9.00$ & $\$ 16.59$ & - \\
\hline $5 \mathrm{~GB}$ & $\$ 11.00$ & $\$ 25.29$ & $\$ 28.91$ \\
\hline $10 \mathrm{~GB}$ & $\$ 22.00$ & $\$ 33.98$ & $\$ 61.52$ \\
\hline
\end{tabular}

Notes: 1. Adapted from BOCRA (2020). Broadband Facts and Figures, December 2020 [40].

2. Prices have been converted from Botswana Pula to US dollar using an average rate of US\$1=BWP10.

\subsection{Existing secondary education online learning platforms}

The Ministry of Basic Education's own e-Thuto project both demonstrates its interest in an e-learning provision and the potential for online teaching and learning at the secondary education level. Launched with the aim to integrate ICT into teaching and learning, the platform's e-learning and data management modules provide learning resources to 35,000 primary and secondary students in piloted public schools in the country's north east region and manages the region's staff and student data [43].

Furthermore, Classmate Online, an online platform founded by 2 local techpreneurs, partners with the Botswana Telecommunications Corporation Limited (BTC) to provide access to secondary education teaching and learning material including content related to the two national secondary education examinations - the Junior Certificate (JC) and the Botswana General Certificate of Secondary Education (BGCSE) examinations. Classmate Online also provides accessibility tools for students living with a range of disabilities such as epileptic safe mode, visually impaired mode, cognitive safe mode and screen reader compatibility [44].

Research Question Two: What challenges may limit WhatsApp's potential use for secondary education teaching and learning in Botswana?

\subsection{Educational, academic, technological and child safety challenges}

The extant research literature indicates that educational, academic, and technical challenges have been associated with WhatsApp's use in secondary education. Educational Challenges arise when teachers are exposed to "conversations that are not compatible with the educational path the school is trying to promote" [24, p. 228]. Teachers face the problem of a potential absence of a boundary between their personal and professional lives. They deal with issues of students' assumptions that teachers 
should be available on a $24 / 7$ basis and the requirement to invest their time beyond regular working hours. Some teachers reported on the disruptive nature of WhatsApp arising from being swamped by messages sent by students during late hours [24].

The disruptive nature of poorly timed messages was also noted by students who also objected to redundant posts within the group [33]. In their investigation of student perspectives on "classroom WhatsApp groups", Rosenberg \& Asterhan [13] found students were cognizant of the information overload possible with WhatsApp's use. The researchers stated that students tried to limit their correspondence within the group because they were aware of the overload created by the constant streams of messages.

Yet another challenge may arise from the sudden shift to online learning as a result of the COVID-19 pandemic. Perifanou et al. [45] noted that at the beginning of the COVID-19 pandemic not all education systems and teachers were prepared to shift to online teaching and learning as they lacked the required digital skills and online teaching experience. According to the 2020 Broadband Commission for Sustainable Development's Working Group on School Connectivity, some teachers may have none or very low levels of digital literacy and little confidence on the use of technology for pedagogical purposes [46].

Teachers also experience Academic Challenges. These arise when students use less formal language and slangs to express themselves on academic issues. Teachers face a dilemma about whether and how grammatical mistakes and inappropriate phrase choices are to be corrected when using WhatsApp [24].

Rosenberg and Asterhan [13] highlighted the Social Pressure that may arise within a WhatsApp classroom group. This peer pressure may occur when:

A public request for help to an identified person obligates this person to respond, even if he/she wishes not to. Moreover, the application enables each user to check which group members have seen his or her sent message, which reduces the other users' perceived freedom to choose whether or not to respond with help.

(pp. 214-215)

The major Technical Challenge arises when not all students possess a smartphone $[24,13]$. Rosenberg and Asterhan [13] noted that students without WhatsApp isolate and miss out on important information for learning. These three types of challenges have the potential to limit WhatsApp's use in secondary education.

While WhatsApp is generally a safe application due to its use of end-to-end encryption (E2EE) [22], Child Safety Challenges may arise because WhatsApp's use entails students spending longer time online than was the case prior to the pandemic [46]. The 2020 Broadband Commission noted that by increasing children's internet connectivity time and reliance on online platforms, the COVID-19 pandemic also increased the risk of their exposure to inappropriate content and cyber-bulling, including online child sexual exploitation and abuse [46]. The Commission also noted that digital devices and platforms, including educational platforms, often lack adequate child safety features. Children may inadvertently record videos or take photos offline and install apps that permit access their devices' storage, leading to the risk of potential image theft and abuse [46].

The research literature [47-50], [10] also indicates that behavioural addiction for mobile phones or mobile phone dependence may arise as students spend longer time online and interfere with learning. Nikolopoulou and Gialamas [51] summarize 
symptoms of dependence found within the literature as preoccupation with the device, excessive use with loss of control, unintended use, use in socially inappropriate situations, adverse effects on relationships, symptoms of withdrawal (e.g., feelings of anger, tension, ringer anxiety, depression when the phone/network becomes inaccessible, signs of craving), symptoms of tolerance (e.g., need for new better phone, more hours of use), and behavioural impairments (e.g., arguments, poor academic achievement, social isolation, communifaking i.e. engaging in fake conversations on mobile phone for purpose of avoiding others). Razzaq et al. [52] notes that WhatsApp use can lead to distraction and procrastination and impede learning. The researchers (p. 103) note that students' practice of "phubbing", a combination of the word "phone" and "snub", leads them to ignore people around them and affects their social skills and studies. These symptoms and practices are possible negative consequences of prolonged online presence as students logon to use WhatsApp for learning.

Research Question Three: What technological and pedagogical competences are critical for teachers to successfully use WhatsApp for m-learning?

While Botswana's teachers likely use WhatsApp regularly for social purposes, their teaching styles and methods and abilities to fully exploit the app's capabilities must reflect the ICT competences required to effectively integrate the app into teaching and learning. According to Redecker [53, p. 15], teachers "need a set of specific competences that will allow them to realise the potential of digital technologies to transform their teaching and learning." Otherwise, as OECD [54, p. 43] found, "the use of digital resources by teachers lacking the appropriate digital skills may form a distraction for pupils and teachers themselves, and so have a negative impact on learning outcomes".

Almerich et al. [55, p. 112] distinguish between technological competences or "teachers' knowledge and skills that allow them to adequately master the technological resources needed for their teaching practice," and pedagogical competences or “teachers' knowledge and skills that allow them to employ technological resources in curricular designs and professional development, and in planning their own teaching and classroom organization" [55, p. 113].

The extant literature indicates several ICT competence frameworks for developing pre- and in-service teachers' technological, pedagogic and other competences. One example is UNESCO's ICT Competency Framework for Teachers [56], which has been applied in several sub-Saharan African countries given its design permits adaptation and contextualization to national education systems. The Framework incorporates 18 ICT competences to which teachers should aspire. The 18 competences are organized according to six aspects of a teacher's professional practice - understanding ICT in education policy; curriculum and assessment; pedagogy; application of digital skills; organization and administration; and teacher professional learning [56]. Another framework is provided in the European Commission's Digital Competence (DigComp) Framework based on five areas and 21 competences. Applied across Europe, digital competence is defined across five areas: information and data literacy; communication and collaboration; digital content creation; safety; and problem solving [57].

Applying UNESCO's Framework, the progressive technological competences that teachers should demonstrate to successfully use WhatsApp, may include the ability to, inter alia [56]: 
- Identify the function of hardware components (e.g., mobile devices) and common software applications, and be able to use them. This includes being able to create text documents, presentations and graphics; navigate the internet to search for digital curriculum resources; demonstrate an understanding of basic principles of cyber safety/security; and use mobile technologies and social networks.

- Blend varied digital tools and resources to create an integrated digital learning environment that supports students' higher-order thinking and problem-solving skills. This includes being able to use digital communication tools (e.g., WhatsApp classroom groups) to support student collaboration and the sharing of digital resources; and source and evaluate digital tools to support students with disabilities.

- Design knowledge communities and use digital tools to support pervasive learning. This includes being able to create an online learning environment using WhatsApp; use digital tools to support online collaboration between students and members of the knowledge community (e.g., by incorporating live video feeds); and encourage students to develop their own digital tools to support learning.

Drawing from UNESCO's Framework, the progressive pedagogical competences that teachers should demonstrate may include the ability to, inter alia [56]:

- Make appropriate choices related to WhatsApp to support specific teaching and learning methodologies. This includes being able to devise lesson plans that incorporate WhatsApp-supported activities to support students' acquisition of subject knowledge; and use presentation software and digital resources to support instruction (e.g., by incorporating accessible WhatsApp's digital media such as audio and video).

- Design WhatsApp-supported project-based learning activities and use WhatsApp to facilitate students to create, implement and monitor project plans, and solve complex problems.

- Encourage student self-management in student-centred and collaborative learning. This includes being able to design online materials and activities that engage students in collaborative, problem-solving research (e.g., devise a set of activities that task students to work together to produce a digital product or artefact); help students create digital media resources that support their learning and interaction with other audiences; and help students reflect on their own learning (e.g., using WhatsApp status or video diaries for sharing reflective experiences).

\section{Conclusion}

\subsection{Discussion and recommendations for policy and practice}

This study was based on the conceptualization of WhatsApp as a boundary object or practice that permits crossover from learning that takes place at a school site to that which takes place outside school. The focus on the m-Learning technology tool was considered warranted for business continuity in Botswana's public secondary education system during and beyond pandemics. As Iserson [58] noted, the COVID-19 pandemic will slowly "pass into memory" only to be replaced in the future by another 
global pandemic. WhatsApp presents a teaching and learning solution in the face of future outbreaks of diseases that may affect school-going in physical institutional facilities. The yet unknown Disease X, for instance, "represents the knowledge that a serious international epidemic could be caused by a pathogen currently unknown to cause human disease [8]."

Findings from this study support WhatsApp's potential as new paradigm and boundary object for teaching and learning. In countries where the app has been used at the secondary educational level, significant technical, educational and academic advantages were observed by both teachers and students. The app was found to be simple, low cost, private in comparison to other social networks such as Facebook and Twitter, and immediately accessible by teachers and students. It created a positive atmosphere and a sense of belonging among students and encouraged problem-solving and realtime teacher-student interaction. Higher test scores were associated with its use. These findings therefore provide the foundation for what Akkerman and Bakker [31] term "Identification"- the recognition of WhatsApp as a legitimate alternative form of teaching and learning that takes place outside school.

Study findings indicate that within the context of Botswana, there are cost advantages to WhatsApp's adoption that arise from the relative affordability of both the required device and internet service. The cheapest suitable smartphone (at US\$ 38) and the cost of one month's internet subscription (from just under US\$ 7) are affordable relative to the average monthly cash earnings (P. 4, 997 or just under US\$ 500) of both citizen and non-citizen wage earners [59].

Botswana has the necessary broadband infrastructure in place. WhatsApp's use for national business continuity at the secondary education level is supported by the country's high mobile penetration rate of over 191 percent, its mobile broadband penetration of 112 percent and its national network coverage of 98 percent. Furthermore, the Ministry of Basic Education has already piloted an online (e-Thuto) learning programme. These findings support the mobility of technology, learning and learners attributed to this form of mobile learning. The cost and infrastructural advantages provide the foundation for what Akkerman and Bakker [31] term "Coordination"_- "boundary permeability" or the seamless movement from learning within-school to learning outside of school.

\subsection{Addressing the equity gap}

It must be noted that WhatsApp's use is also accompanied by challenges for learners, teachers, school administrators and the Ministry of Basic Education. The extant research literature indicates that a major technical challenge to the app's use occurs when not all students possess a smartphone. An equity gap may therefore impede the transition to what Akkerman and Bakker [31] term "Reflection" and "Transformation," that is, key stakeholders' perception and acceptance of WhatsApp as a new paradigm for teaching and learning [46]. An equity gap arises when students experience different educational outcomes because of their parents' socioeconomic status or their own gender, disability or other characteristic.

The litmus test that no secondary school student in Botswana will be left behind in terms of education via WhatsApp, is therefore whether students from poor families, especially rural poor families, will be able to afford a smartphone and the monthly 
internet service charges, and whether access will be inclusive for all groups including children living with disabilities.

In the context of Botswana, poverty levels may exacerbate this potential equity gap. While the cheapest smartphones are available from US\$ 38 each and the cost of one month's internet subscription ranges from just under US\$ 7 , this one-off device cost and monthly recurring service charge may be unaffordable to those in extreme poverty living at or below the international poverty rate of US\$1.90 per person/day or US\$50 per person/month, and those living in areas of highest poverty in the country such as in the Kweneng West, Ngwaketse West and Kgalagadi South districts [60].

To overcome this potential equity gap, we recommend that government provides a financial incentive to disadvantaged families as part of an educational demand-side policy. Specifically, we recommend that conditional cash transfers (CCTs) be provided to disadvantaged families with children in secondary education, whereby parents or caregivers receive a monthly cash grant on condition that their children participate in WhatsApp teaching and learning. The precise targeting on families with children in secondary education may facilitate implementation success. Conditional cash transfers have been successful in several countries such as Brazil's Bolsa Familia, Colombia's Familias en Acción, and Mexico's Progresa/Oportunidades/Prospera and target children with specific vulnerabilities, such as extreme poverty, remoteness, caste and gender, and indigenous populations [61]. CCTs have been found to have positive effects on poverty, education, health and future outcomes [62]. Mexico's Progresa programme increased secondary enrollment, attendance and the number of school grades completed [63-64]. Brazil's Bolsa Familia programme increased enrollment rates and mean years of schooling in that country [65-66]. A meta-analysis of 25 studies found that conditional CCTs improved both enrollment and the likelihood of a child being enrolled by $41 \%$ [67].

We also recommend that the government pursue a blended approach to teaching and learning when the necessary infrastructure does not exist to support WhatsApp's use (e.g., villages not yet electrified or outside the broadband network). Parents may use the transfer to cover transportation costs to schools where the reduced student presence will satisfy both the social distancing requirement of the government's COVID-19 regulations and teacher-student interaction. We also recommend that the private sector be encouraged to assist these families or help fund the cash grants as part of their corporate social responsibility.

Learning for students with disabilities should be examined. To ensure inclusive education for people with sensory, motor, and mild cognitive impairment, we recommend the Ministry's IT department propose ways teachers can avoid potential learning impediments that may arise, for example, from inappropriate shapes and confusing graphics labels and page layouts [68].

\subsection{Addressing the digital gap}

The extant research literature indicates that WhatsApp's use in secondary education is accompanied by several teacher-affecting educational and academic challenges. They include the heavy demands on teacher availability and the need for new approaches to 
deal with students' online grammatical mistakes and use of inappropriate phrases, and skills to use the technology for teaching and learning. A digital gap may occur among teachers in terms of the adequacy of their digital literacy skills [46].

To overcome the educational and academic challenges and digital divide faced by teachers, we recommend training to prepare teachers for their new roles and the effective management of WhatsApp classroom groups. The 2020 Broadband Commission recognized that teachers will need to be equipped with sharper ICT competencies as well as assessment and pedagogical skills required to implement the online curricula and differentiated learning strategies [46]. Teachers should be provided with progressive pre- and in-service training to develop the requisite technological and pedagogical competences.

Such training will enable teachers to hone their teaching methods and styles towards the effective use of the app's technology and capabilities. The training will enable teachers to understand the meaning and requirements of online accessibility to students in the digital age. As An \& Frick [69, p. 486] report, in comparison with face-to-face communication, text-based computer-mediated communication lacks visual and auditory cues. The training will enable teachers to be cognizant of the need to "translate" through their choice of words and response rates, the same levels of encouragement and support they would otherwise communicate in a face-to-face encounter in the traditional classroom. Teachers will learn how to be careful with their choice of words to compensate for the absence of body language, gestures and other contextual cues that convey important meanings [69].

Teachers also need to be trained to use digital tools for such activities as curriculum development and management, managing courses, monitoring students and educational resources, giving guidance and feedback to the students, and evaluating students [45].

Efforts are underway in this regard. The Minister of Basic Education informed the country's Parliament that the Ministry is pursuing an initiative to ensure teachers are proficient in ICT use and have the expertise and technical skills required to develop and source relevant e-content for learning facilitation [70]. To complement this initiative, Botswana may engage UNESCO to explore the possibility of future support similar to UNESCO's previous Competence Framework CFIT project "Enhancing Teacher Education for Bridging the Education Quality Gap in Africa," that facilitated pre- and in-service teacher ICT training in 10 sub-Saharan African countries [71].

To assist quality assurance in terms of online teaching delivery, we also recommend the government negotiate with internet service providers so that reduced-price modems are procured and reduced monthly internet charges availed to teachers.

\subsection{Addressing the safety gap}

This study proposed the use of WhatsApp as a tool for secondary education during and beyond a pandemic. A safety gap may arise from the longer periods of time students will be required spend online, in comparison to before the COVID-19 pandemic. We endorse the Commission's recommendation of mandatory education on Child Online Safety (COS) for students, teachers, parents and caregivers so that they are empowered with information about how to respond to and report harmful content and abuse, and 
children understand how the digital world works [46]. We also recommend that issues and symptoms related to the negative effects on students in terms of mobile phone dependency must form part of preparatory teacher training and the education of the students, parents and stakeholders. The government should ensure that students and their parents and caregivers are prepared for online learning before WhatsApp is accepted as a new paradigm for teaching and learning.

\subsection{Generalization to primary education}

Study findings support WhatsApp's potential as a new paradigm and boundary object for secondary education teaching and learning. We consider findings to be generalizable to primary education with greater reliance on WhatsApp's asynchronous communication in addition to regular teaching with students via WhatsApp's classroom groups. Higher parental involvement and monitoring will be required to assure learning takes place and child safety online.

\subsection{Concluding thoughts}

At least three conclusions were drawn from the findings of this study. First, WhatsApp has potential as a m-Learning technology tool for the public secondary education system in Botswana even in the absence of a pandemic, given the technological, educational and academic advantages it affords learners, its affordability, and the country's high mobile phone penetration and extensive mobile broadband network. Second, WhatsApp's successful adoption for public secondary education will rely on the government's ability to ensure access by those children at risk of being left behind, teacher preparation (i.e. training and equipping), and children's online safety. Third, WhatsApp's use as the top messenger app in use across Botswana and its capabilities (i.e. for synchronous teaching within secondary education and asynchronous teaching within primary education) complements existing efforts to integrate ICT into teaching and learning and embrace the digital age.

Future research will seek to further investigate WhatsApp's potential for Botswana's education sector. Research will examine user profiles of the existing e-Thuto and Classmate Online programmes, the academic and educational effects of these programmes for secondary school students and teachers, and their impact on students' examination results. The ease of boundary crossing of these platforms relative to WhatsApp will be explored. With the continued emergence of new and more contagious COVID-19 variants of interest and concern, the future yet unknown effects of a possible "Disease $X$ " and the need to transform all branches (primary, secondary and tertiary) of education through digitalization, there are clear signals that educational administrators must implement a plan of action today that will assure the continuity of schooling and the future educational attainment of Botswana's children.

\section{$7 \quad$ Acknowledgment}

The authors wish to thank the Botswana Communications Regulatory Authority (BOCRA) for granting permission for the use of its data in this study. 


\section{$8 \quad$ References}

[1] World Bank. (2021). Urgent, effective action required to quell the impact of COVID-19 on education worldwide. World Bank.

[2] United Nations (2020). Policy Brief: Education during COVID-19 and beyond. United Nations.

[3] Mmegi Online (2020, April 10). Minister of Basic Education press briefing. Retrieved from https://www.facebook.com/MmegiOnline/videos/2309928739310244/

[4] Mmegi Online (2020, April 7). Telecommunications service providers press briefing. Retrieved from https:/www.facebook.com/MmegiOnline/videos/249247076253848/

[5] Botswana Communications Regulatory Authority (2020). Public notice: BOCRA approves reduction in prices for internet data bundles. Retrieved from https://www.bocra.org.bw/ public-notice-bocra-reduction-prices-internet-data-bundles

[6] World Bank (2021). Population, total - Botswana. Retrieved from https://data.worldbank. org/indicator/SP.POP.TOTL?locations $=$ BW

[7] Kemp, S. (2020). Digital 2020: Botswana. Retrieved from https://datareportal.com/reports/ digital-2020-botswana

[8] World Health Organization (n.d.). Prioritizing diseases for research and development in emergency contexts. Retrieved from https://www.who.int/activities/ prioritizing-diseases-for-research-and-development-in-emergency-contexts

[9] Joyce-Gibbons, A., Galloway, D., Mollel, A., Mgoma, S., Pima, M., \& Deogratias, E. (2018). Mobile phone use in two secondary schools in Tanzania. Education and Information Technologies, 23(1), 73-92. https://doi.org/10.1007/s10639-017-9586-1

[10] Nikhita, C. S., Jadhav, P. R., \& Ajinkya, S. A. (2015). Prevalence of mobile phone dependence in secondary school adolescents. Journal of Clinical and Diagnostic Research, 9(11), VC06-VC09. https://doi.org/10.7860/JCDR/2015/14396.6803

[11] Walsh, S. P., White, K. M., Cox, S., \& Young, R. M. (2011). Keeping in constant touch: The predictors of young Australians' mobile phone involvement. Computers in Human Behavior, 27(1), 333-342. https://doi.org/10.1016/j.chb.2010.08.011

[12] Rambe, P., \& Crispen, C. (2013). Using mobile devices to leverage student access to collaboratively-generated resources. Proceedings of the 2013 International Conference on Advanced ICT and Education, 331-337. Atlantis Press. https://doi.org/10.2991/icaicte.2013.66

[13] Rosenberg, H., \& Asterhan, C. S. C. (2018). “WhatsApp, Teacher?"-Student perspectives on teacher student WhatsApp interactions in secondary schools. Journal of Information Technology Education: Research, 17, 205-226. https://doi.org/10.28945/4081

[14] Alexander, B. (2004). Going nomadic: Mobile learning in higher education. Educause Review, 39(5), 28-35.

[15] Ally, M. (2005). Using learning theories to design instruction for mobile learning devices. In J. Attewell, J. \& C. Savill-Smith (Eds.), Mobile learning anytime everywhere. Learning and Skills Development Agency.

[16] Traxler, J. (2007). Defining, discussing and evaluating mobile learning: The moving finger writes and having writ... International Review of Research in Open and Distance Learning. 8(2), 1-12. https://doi.org/10.19173/irrodl.v8i2.346

[17] Quinn, C. (2001). mLearning: mobile, wireless, in-your-pocket learning. Retrieved from https://www.researchgate.net/publication/343083598 mLearning_Mobile Wireless In-Your- Pocket Learning

[18] El-Hussein, M. O. M., \& Cronje, J. C. (2010). Defining mobile learning in the higher education landscape. Educational Technology \& Society, 13(3), 12-21.

[19] Rambe, P., \& Bere. A. (2013). Using mobile instant messaging to leverage learner participation and transform pedagogy at a South African University of Technology. British Journal of Educational Technology, 44(4), 544-561. https://doi.org/10.1111/bjet.12057 
[20] Walker, K. (2007). Introduction: Mapping the landscape of mobile learning. In M. Sharples (Ed.), Big issue in mobile learning: A report of a new workshop by the Kaleidoscope Network of Excellence Mobile Learning Initiative (pp. 5-6), UK: Learning Science and Research Institution: University of Nottingham.

[21] Robles, H., Guerrero, J., Llinás, H., \& Montero, P. (2019). Online teacher- students ${ }^{\text {ce inter- }}$ actions using WhatsApp in a law course. Journal of Information Technology Education: Research, 18, 231-252. https://doi.org/10.28945/4321

[22] WhatsApp (2021). WhatsApp. Retrieved from https://www.whatsapp.com/?lang=en

[23] Bower, M. (2008). Affordance analysis - Matching learning tasks with learning technologies. Educational Media International, 45(1), 3-15. https://doi.org/10.1080/09523980701847115

[24] Bouhnik, D., \& Deshen, M. (2014). WhatsApp goes to school: Mobile instant messaging between teachers and students. Journal of Information Technology Education: Research, 13, 217-231. https://doi.org/10.28945/2051

[25] Errico, S. M. (2020). Examples of how to use WhatsApp in education. Retrieved from https://woztell.com/examples-of-how-to-use-whatsapp-in-education/

[26] Bernstein, B. (1971). Class, codes and control. Routledge.

[27] Engeström, Y., Engeström, R., \& Kärkkäinen, M. (1995). Polycontextuality and boundary crossing in expert cognition: Learning and problem solving in complex work activities. Learning and Instruction, 5, 319-336. https://doi.org/10.1016/0959-4752(95)00021-6

[28] Star, S. L. (1989). The structure of ill-structured solutions: Boundary objects and heterogeneous distributed problem solving. In L. Gasser \& M. Huhns (Eds.), Distributed artificial intelligence (pp. 37-54). Morgan Kaufmann. https://doi.org/10.1016/ B978-1-55860-092-8.50006-X

[29] Star, S. L. (2010). This is not a boundary object: Reflections on the origin of a concept. Science, Technology, \& Human Values, 35, 601-617. https://doi.org/10.1177/0162243910377624

[30] Suchman, L. (1994). Working relations of technology production and use. Computer Supported Cooperative Work, 2, 21-39. https://doi.org/10.1007/BF00749282

[31] Akkerman, S. F., \& Bakker, A. (2011). Boundary crossing and boundary objects. Review of Educational Research, 81, 132-169. https://doi.org/10.3102/0034654311404435

[32] Williams, J., \& Wake, G. (2007). Black boxes in workplace mathematics. Educational Studies in Mathematics, 64, 317-343. https://doi.org/10.1007/s10649-006-9039-z

[33] Cetinkaya, L. (2017). The impact of WhatsApp use on success in education process. International Review of Research in Open and Distributed Learning, 18(7), 59-74. https://doi. org/10.19173/irrodl.v18i7.3279

[34] Jafari, S., \& Chalak, A. (2016). The role of WhatsApp in teaching vocabulary to Iranian EFL learners at junior high school. English Language Teaching, 9(8), 85-92. https://doi. org/10.5539/elt.v9n8p85

[35] Marshall, J. (2002). Learning with technology. Evidence that technology can, and does, support learning. Cable in the Classroom.

[36] Newzoo (2020). Global mobile market report 2020. Retrieved from https://newzoo.com/ insights/trend-reports/newzoo-global-mobile-market-report-2020-free-version/

[37] Lesemela, K. (2021, May 28). Internet connectivity remains high. Botswana Guardian. BG Business, pp. 23-24.

[38] Botswana Communications Regulatory Authority (2020). Telecoms stats. Retrieved from https://www.bocra.org.bw/telecoms-statistics

[39] Statistics Botswana (2021). Information and Communication Technology Stats Brief Q1, 2021. Statistics Botswana. https://doi.org/10.5089/9781513594422.002

[40] Botswana Communications Regulatory Authority (2020). Broadband facts and figures, December 2020. BOCRA. 
[41] Alliance for Affordable Internet (2020). 2020 Affordability Report. Retrieved from https:// a4ai.org/affordabilityreport/report/2020/\#: :text=What $\% 20$ is $\% 20$ the $\% 20$ Affordability $\% 20$ Drivers, ultimately $\% 20$ create $\% 20$ more $\% 20$ affordable $\% 20$ broadband

[42] Lesemela, K. (2021, June 4). BoFiNet faces tough competition. Botswana Guardian. BG Business, p. 19.

[43] Olukotun, O. (2020). Botswana e-learning platform E-Thuto bags UN Public Service Award. Retrieved from https://innovation-village.com/botswana-e-learning-platform-ethuto-bags-un-public-service-award/

[44] Botswana Telecommunications Corporation Limited (2021). Classmate e-learning bundles. Retrieved from https://btc.bw/classmate-powered-by-btc-mobile/

[45] Perifanou, M., Economides, A. A., \& Tzafilkou, K. (2021). Teachers' digital skills readiness during COVID-19 pandemic. The International Journal of Emerging Technologies in Learning, 16(8), 238-251. https://doi.org/10.3991/ijet.v16i08.21011

[46] International Telecommunication Union, United Nations Educational, Scientific and Cultural Organization, and United Nations Children's Fund (2020). The digital transformation of education: Connecting schools, empowering learners. Broadband Commission for Sustainable Development's Working Group on School Connectivity.

[47] Bianchi, A., \& Phillips, J. G. (2005). Psychological predictors of problem mobile phone use. Cyberpsychology, Behavior and Social Networking, 8(1), 39-51. https://doi.org/10.1089/ cpb.2005.8.39

[48] Chóliz, M. (2012). Mobile-phone addiction in adolescence: The test of mobile phone dependence (TMD). Progress in Health Sciences, 2(1), 33-44.

[49] Leung, L. (2008). Linking psychological attributes to addiction and improper use of the mobile phone among adolescents in Hong Kong. Journal of Children \& Media, 2(2), 93-113. https://doi.org/10.1080/17482790802078565

[50] Lopez-Fernandez, O., Honrubia-Serrano, L., Freixa-Blanxart, M., \& Gibson, W. (2014). Prevalence of problematic mobile phone use in British adolescents. Cyberpsychology, Behavior and Social Networking, 17(2), 91-98. https://doi.org/10.1089/cyber.2012.0260

[51] Nikolopoulou, K., \& Gialamas, V. (2018). Mobile phone dependence: Secondary school pupils' attitudes. Education and Information Technologies, 23(26), 2821-2839. https://doi. org/10.1007/s10639-018-9743-1

[52] Razzaq, A., Samiha, Y. T., \& Anshari, M. (2018). Smartphone habits and behaviors in supporting students self-efficacy. The International Journal of Emerging Technologies in Learning, 13(2), 94-109. https://doi.org/10.3991/ijet.v13i02.7685

[53] Redecker, C. (2017). European Framework for the Digital Competence of Educators: DigCompEdu. Luxembourg: Publications Office of the European Union.

[54] OECD (2019). How's life in the digital age? Opportunities and risks of the digital transformation for people's well-being. OECD. https://doi.org/10.1787/9789264311800-en

[55] Almerich, G., Orellana, N., Suarez-Rodríguez, J., \& Díaz- García, I. (2016). Teachers' information and communication technology competences: A structural approach. Computers \& Education, 100, 110-125. https://doi.org/10.1016/j.compedu.2016.05.002

[56] UNESCO (2018). UNESCO ICT Competency Framework for Teachers version 3. UNESCO. Retrieved from https://en.unesco.org/themes/ict-education/competency-framework-teachers

[57] European Commission/EACEA/Eurydice (2019). Digital Education at School in Europe. Eurydice Report. Publications Office of the European Union.

[58] Iserson, K. V. (2020). The next pandemic: Prepare for "Disease X.". Western Journal of Emergency Medicine, 21(4), 756-758. https://doi.org/10.5811/westjem.2020.5.48215

[59] Statistics Botswana (2021). Quarterly Multi-Topic Survey: Labour Force Module Report Quarter 4: 2020. Statistics Botswana. 
[60] Statistics Botswana (2018). Botswana Multi-Topic Household Survey Report 2015/16. Statistics Botswana.

[61] Independent Evaluation Group (2011). Evidence and lessons learned from impact evaluations on social safety nets. Independent Evaluation Group, World Bank.

[62] United Nations Educational, Scientific and Cultural Organization (2015). Education for all 2000-2015: Achievements and challenges. UNESCO.

[63] Behrman, J. R., Parker, S. W., \& Todd, P. (2010). Do conditional cash transfers for schooling generate lasting benefits? A five-year followup of PROGRESA/Oportunidades. The Journal of Human Resources, 46(1), 93-122. https://doi.org/10.3368/jhr.46.1.93

[64] Behrman, J. R., Sengupta, P., \& Todd, P. (2000). The impact of PROGRESA on achievement of test scores in the first year. International Food Policy Research Institute.

[65] Soares, S. (2012). BolsaFamilia, its design, its impacts and possibilities for the future. Working Paper 89. International Policy Center for Inclusive Growth, Brasilia.

[66] Glewwe, P., \& Kassouf, A. L. (2008). What is the impact of the Bolsa Familia programme on education? OnePager 107. International Policy Centre for Inclusive Growth, Brasilia.

[67] Baird, S., Ferreira, F. H. G., Özler, B., \& Woolcock, M. (2013). Relative effectiveness of conditional and unconditional cash transfers for schooling outcomes in developing countries: A systematic review. The Campbell Collaboration. https://doi.org/10.4073/csr.2013.8

[68] Hafiar, H., Subekti, P., \& Nugraha, A. R. (2019). Internet utilization by the students with visual impairment disabilities. The International Journal of Emerging Technologies in Learning, 14(10), 200-207. https://doi.org/10.3991/ijet.v14i10.10057

[69] An, Y. J., \& Frick, T. (2006). Student perceptions of asynchronous computer-mediated communication in face-to-face courses. Journal of Computer-Mediated Communication, 11(2), 485-499. https://doi.org/10.1111/j.1083-6101.2006.00023.x

[70] Thobega, K. (2021, August 11). MoBE connects internet in schools. The Midweek Sun, p. 3.

[71] UNESCO (n.d.). Enhancing teacher education in Africa. UNESCO. Retrieved from https:// en.unesco.org/themes/teachers/cfit-teachers

\section{Authors}

Dawn Lyken-Segosebe is a Senior Lecturer at the Botswana International University of Science and Technology, Palapye, Botswana. She holds a PhD in Leadership and Policy Studies and MA degree in Economics from Vanderbilt University, USA. Her research interests include the scholarly and teaching role performance of college and university faculty, online teaching and learning, colleges and universities as organizations, and the internationalization of higher education. She is a member of the Editorial Review Board of the journal Innovative Higher Education. Email: segosebed@biust. $\underline{\text { ac.bw }}$

Gladys Gamariel is a trained economist, researcher and educator and currently teaches Economics, Management and Entrepreneurship to Science and Engineering majors at the Botswana International University of Science and Technology, Palapye, Botswana. Her research interests include integration of Arts in STEM curricula, women economic empowerment, economic diversification in resource-dependent low-income countries, and small and medium scale enterprise management. Email: gamarielg@, biust.ac.bw 
Kelebonye Bagai is a Teaching Instructor at the Botswana International University of Science and Technology, Palapye, Botswana. He holds a Master's degree in Communication, Culture and Media from Coventry University, UK and a Postgraduate Diploma in Education from the University of Botswana, Gaborone, Botswana. He was an inductee of the Global Leadership Programme, Coventry University, UK. His research interests include curriculum evaluation, communication theory, media theory, media representation and discourse analysis. Email: bagaik@biust.ac.bw

Article submitted 2021-09-23. Resubmitted 2021-11-08. Final acceptance 2021-11-08. Final version published as submitted by the authors. 